\title{
Heave and pitch motions performance of a monotricat ship in head-seas
}

\author{
A. Fitriadhy* and N. Amira Adam \\ Program of Maritime Technology, School of Ocean Engineering, \\ Universiti Malaysia Terengganu, Malaysia. \\ *Email: naoe.afit@gmail.com \\ Phone: +6096683856; Fax: +6096683193
}

\begin{abstract}
A reliable investigation which allows an accurate prediction on seakeeping performance of a monotricat ship in head-seas is obviously required. To achieve this objective, a Computational Fluid Dynamic simulation approach is proposed by looking into attainable outcomes with precision, whilst a hydrodynamic description that is underlying the rationale behind the results is explained. Two conditions of the monotricat ship model, termed as with and without stepped-hull, were employed in the computational simulation. Several wave properties, such as various wavelengths and wave heights on heaving and pitching performances associated with different Froude number (Fr) were taken into account. The results showed that the increase of Fr was proportional with the increase the heaving and pitching motions. These led to the downgrade seakeeping performances presented in the form of high Response Amplitude Operators (RAO). In shorter wavelengths $(\lambda<1)$, RAO of the heave and pitch motions were insignificant. However, the subsequent increase of wavelength $(\lambda>1)$ was proportional with the increased RAO of the heave and pitch motions. The further increase in wavelength $(>1.75)$ resulted in less RAO both of the heave and pitch motions. The increase in wave height had affected a proportionate increase in the heave and pitch motions that may possibly lead to degrade her seakeeping quality. It can be concluded that the effects of Fr and wavelength on the heave and pitch motions of the monotricat ship had more complex phenomenon as compared to the wave-height ones. These CFD results are useful as preliminary prediction for navigation safety during sailing.
\end{abstract}

Keywords: Monotricat; CFD; heave motion; pitch motion; RAO; Froude number; wavelength; wave height.

\section{INTRODUCTION}

A Monotricat ship is one of the high-speed vessels which offer some advantages as compared to multi-hull ships, such as high efficiency of resistance and maneuverability. According to the Nautical International magazine, the monotricat ship promises to beat the speed limitations of displacement hull albeit preserving their positive aspects of comfort and thriftiness" [1]. This is particularly true when a monotricat design is capable of archiving $20 \%$ of efficiency because of the resistance reduction and benefit to the increase in speed (hydrodynamics effect raises the bow compensating lifting stern) [2]. As a common ship, a seakeeping performance of monotricat ship is a very prominent aspect to be analysed in the early design stage to consider the flexibility is the reason for preferring the monotricat predictions of performance in a regular wave condition. There is a number 
of way to estimating the behavior of the ship when is subjected to waves. Several researchers had studied on the modelling a seakeeping performance of ship both by using numerical and experimental approaches. [3], Fonseca et al. [4], Belknap [5], Bailey et al. [6], Fernández [7], and Ogilvie and Tuck [8] investigated on seakeeping analysis by using the strip theory method. Besides that, seakeeping was also predicted by using an experimental model test with towing tank [9], [10], [11], and [12]. This experimental method is very costly, time-consuming, and have a complex procedure. In particular, this approach is relatively expensive, time-consuming and even impractical for various seakeeping test configurations. It became obvious that a reliable Computational Fluid Dynamic (CFD) approach has become a necessary aim to gain more accurate predictions as compared to the experimental model test [13], [14], and [15].

This paper presents a Computational Fluid Dynamics (CFD) simulation approach to analyses seakeeping performance of a monotricat ship in head-seas regular waves. Here, a commercial CFD software, namely NUMECA Fine Marine v3.1-1, is utilised by applying the incompressible unsteady Reynolds Averaged Navier Stokes Equation (RANSE). This RANSE and continuity equations are discretised by the finite volume method based on Volume of Fluid (VOF) to deal with the non-linear free surface. In addition, the computational domain with adequate numbers of grid meshes of the monotricat ship was carefully determined before simulations. Basically, this is solved by means of a mesh independent study to estimate the optimal domain discretisation. In this computational simulation, several parameters, such as effect of Froude numbers (Fr), wavelengths and wave heights are considered. Two conditions of the monotricat ship model, namely with and without stepped-hull, are employed in the simulation. The results are then comprehensively discussed to point out the aforementioned parameters, which are presented in the form of response amplitude operator of the heave and pitch motions characteristics.

\section{METHODS AND MATERIALS}

The CFD flow solver on NUMECA FINE/Marine 3.1-1 is based on the incompressible unsteady RANSE, in which the solver applies the Finite Volume Method to build the spatial discretisation of the transport equations. In addition, the velocity field is obtained from the momentum equations and the pressure field is extracted from the mass conservation constraint, or continuity equation, transformed into a pressure equation. In the case of turbulent flows, additional transport equations for modelled variables are solved in a form similar to that of the momentum equations and they can be discretised and solved by using the same principles. Furthermore, the non-linear free surface flow is treated as the interface between air and water, which are assumed to be incompressible and isotropic Newtonian fluid.

\section{Conservation Equations}

The flow solver can deal with multi-phase flows and moving grids. The incompressible flow of viscous fluid under isothermal conditions, mass, momentum and volume fraction conservation equations can be expressed as (by using the generalised form of Gauss' Theorem):

$$
\frac{\partial}{\partial_{t}} \int_{S} \rho\left(\vec{U}-\vec{U}_{d}\right) \cdot \vec{n} d S=0
$$




$$
\begin{aligned}
& \frac{\partial}{\partial_{t}} \int_{V} \rho U_{i} d V+\int_{S} \rho U_{i}\left(\vec{U}-\vec{U}_{d}\right) \cdot \vec{n} d S=\int_{S}\left(\tau_{i j} I_{j}-p I_{i}\right) \cdot \vec{n} d S+\int_{V} \rho g_{i} d V \\
& \frac{\partial}{\partial_{t}} \int_{V} c_{i} d V+c_{i}\left(\vec{U}-\vec{U}_{d}\right) \cdot \vec{n} d S=0
\end{aligned}
$$

where $V$ is the control volume, bounded by the closed surface $\mathrm{S}$ with a unit normal vector $\vec{n}$ directed outward that moves at the velocity $\vec{U}_{d}$ with a unit normal vector $\vec{n}$. The notation of $\vec{U}$ and $p$ represents the velocity and pressure fields, respectively. $\tau_{i j}$ and $g_{i}$ define the components of the viscous stress tensor and the gravity vector, respectively; whereas $I_{j}$ is a vector whose components vanish, except for the component $j$ which is equal to unity. $c_{i}$ is the $i^{\text {th }}$ volume fraction for fluid $i$ and is used to distinguish the presence $\left(c_{i}=1\right)$ or the absence $\left(c_{i}=0\right)$ of $i^{\text {th }}$ fluid. Since a volume fraction between 0 and 1 indicates the presence of a mixture, the value of $1 / 2$ is selected as a definition of the interface.

\section{Turbulence Model}

In this turbulence model, we propose the SST k- $\omega$ (SST for shear-stress transport) model, which is available inside ISIS-CFD solver code, where $k$ is the turbulent kinetic energy and $\omega$ is the specific dissipation rate. [16], Menter [17], Menter [18] and Menter [19] reported that the SST k- $\omega$ model combines several desirable elements of existing twoequation models. The two major features of this model are a zonal blending of model coefficients and a limitation on the growth of the eddy viscosity in rapidly strained flows. The zonal modelling uses Wilcox's $k-\omega$ model near solid walls and the standard $k-\varepsilon$ model, in a $k-\omega$ formulation, near boundary layer edges and in free-shear layers. [20], Baldwin and Barth [21] highlighted that the SST $k-\omega$ model here is set to improve the predictions obtained with algebraic mixing-length models to develop a local model for complex flows, and to provide a simpler alternative to two-equation turbulence models. This means that this turbulent model improves the prediction of flows with strong adverse pressure gradients and separation.

The two transport equations of the model are defined below with a blending function $F_{1}$ for the model coefficients of the original $\omega$ and $\varepsilon$ model equations and are written as:

$$
\begin{aligned}
& \frac{\partial \rho K}{\partial t}+\frac{\partial}{\partial x_{j}}\left(\rho U_{j} K-\left(\mu+\sigma_{k} \mu_{t}\right) \frac{\partial K}{\partial x_{j}}\right)=\tau_{i j} S_{i j}-\beta^{*} \rho \omega K \\
& \frac{\partial \rho \omega}{\partial t}+\frac{\partial}{\partial x_{j}}\left(\rho U_{j} \omega-\left(\mu+\sigma_{\omega} \mu_{t}\right) \frac{\partial \omega}{\partial x_{j}}\right)=P_{\omega}-\beta \rho \omega^{2}+2\left(1-F_{1}\right) \frac{\rho \sigma_{\omega 2}}{\omega} \frac{\partial K}{\partial x_{j}} \frac{\partial \omega}{\partial x_{j}}
\end{aligned}
$$

where the last source term of Equation (5) represents the cross-diffusion term that appears in the transformed $\omega$-equation from the original $\varepsilon$-equation. Menter and Rumsey [22] noted that the production term of $\omega$ is sometimes approximated as proportional to the absolute value of vorticity:

$$
P_{\omega}=2 \gamma \rho\left(S_{i j}-\frac{\omega S_{n n} \delta_{i j}}{3}\right) S_{i j} \cong \gamma \rho \Omega^{2}
$$


The auxiliary blending function $F_{1}$, designed to blend the model coefficients of the original $\mathrm{k}-\omega$ model in boundary layer zones with the transformed $\mathrm{k}-\varepsilon$ model in free-shear layer and free-stream zones, is defined as follows:

$$
F_{1}=\max \left\{\left[\min \left\{\max \left\{\frac{\sqrt{K}}{0.09 d \omega}, \frac{500 \mu}{\rho d^{2} \omega}\right\}, \frac{4 \varnothing \sigma_{\omega 2} k}{C D_{k \omega} d^{2}}\right\}\right]^{4}\right\}
$$

where $C D_{k \omega}=\max \left\{\frac{2 \rho \sigma_{\omega 2}}{\omega} \frac{\partial K}{\partial X_{J}} \frac{\partial \omega}{\partial X_{J}}, 10^{-20}\right\}$. Here, $C D_{k \omega}$ is the cross-diffusion in the $\mathrm{k}-\omega$ model.

It should be noted here that when calculating turbulence quantities, it is important to consider an appropriate cell meshing size. This can be explained by the fact that during computations using the Navier-Stokes equations the boundary layer near a solid wall contains high gradients. To properly capture it a sufficient number of grid points inside the boundary layer is essential. Here, an appropriate estimation of the cell meshing size $y_{\text {wall }}$ for Navier-Stokes simulations including turbulence depends on the local Reynolds number, which is computed based on the wall variable $y^{+}$. This is a $y^{+}$dimensionless parameter representing local Reynolds number in the near wall region. Referring to [23], the value of $y^{+}$value associated with the first node near the wall will be referred to as $y_{1}^{+}$, where the equation of $y_{1}^{+}$can be written as:

$$
y_{1}^{+}=\frac{\rho u_{\tau} y_{\text {wall }}}{\mu}
$$

where $u_{\tau}$ is the friction velocity, $u_{\tau}=\sqrt{\frac{\tau_{\text {wall }}}{\rho}}=\sqrt{\frac{1}{2} \rho\left(V_{\text {ref }}\right)^{2} C_{f}}$. It is clear that the value of $y_{\text {wall }}$ depends on the value of $y_{1}^{+}$.

In addition, the estimation for $y_{\text {wall }}$ as a function of a desired $y_{1}^{+}$value is obtained using a truncated series solution of the Blasius equation as written in Equation (9) below.

$$
y_{\text {wall }}=6\left(V_{\text {ref }} / v\right)^{-7 / 8}\left(L_{\text {ref }} / 2\right)^{1 / 8} y_{1}^{+}
$$

Note that the reference velocity, $V_{\text {ref }}$, can be taken from the body velocity. The reference length, $L_{r e f}$, should be based on the body length since an estimation of the boundary layer thickness is implied in this calculation. For instance, in the case of a marine simulation, one can use the boat length, or the length between perpendiculars, as reference length. This refers to the length of a vessel along the waterline from the forward surface of the stem, or main bow perpendicular member, to the after surface of the sternpost, or main stern perpendicular member. This is approximate, of course, as the thickness of the boundary layer will vary widely within the computational domain. Fortunately, it is only necessary to place $y_{1}^{+}$within a range and not at a specific value.

\section{Heave and Pitch Motion}

The degree of freedom (D.O.F) represented the possible translations and rotation of the body. The heave and pitch motion noted as translation and rotation, respectively along $\mathrm{X}$, $\mathrm{Y}$, and Z-axis that define the behaviour of the monotricat ship in seaway. The coupled equation of heave and pitch motions are solved in the time-domain for regular waves. 
These equations are demonstrated as follows:

$$
\begin{aligned}
& \left(M+A_{33}\right) \frac{d^{2} \eta_{3}}{d t^{2}}+B_{33} \frac{d \eta_{3}}{d t}+\mathrm{C}_{33} \eta_{3}+\mathrm{A}_{35} \frac{d^{2} \eta_{5}}{d t^{2}}+B_{35} \frac{d \eta_{5}}{d t}+\mathrm{C}_{35} \eta_{5}=F_{3} \\
& A_{53} \frac{d^{2} \eta_{3}}{d t^{2}}+B_{53} \frac{d \eta_{3}}{d t}+\mathrm{C}_{53} \eta_{3}+\left(\mathrm{I}_{55}+\mathrm{A}_{35}\right) \frac{d^{2} \eta_{5}}{d t^{2}}+B_{35} \frac{d \eta_{5}}{d t}+\mathrm{C}_{55} \eta_{5}=F_{5}
\end{aligned}
$$

In these equations, $\mathrm{M}$ is the vessel mass, $\mathrm{I}_{55}$ is the moment of inertia in pitch and $\mathrm{A}_{\mathrm{ij}}, \mathrm{B}_{\mathrm{ij}}$ and $\mathrm{C}_{\mathrm{ij}}$ are coefficients of added mass, damping and restoring coefficient respectively. Also, $\mathrm{F}_{3}$ and $\mathrm{F}_{5}$ are the vertical force and longitudinal subverting moment on the vessel respectively [24].

\section{Simulation Conditions}

The principal dimension of the monotricat ship, which composes of the three hull type combinations, i.e. monohull, trimaran and catamaran are presented in Table 1. Figure 1 shows the body plan and rendered hull with the stepped-hull and without stepped-hull.

Table 1. Principle dimensions of monotricat (with and without stepped-hull configurations).

\begin{tabular}{lcc}
\hline \multicolumn{1}{c}{ Descriptions } & Stepped-hull & Without stepped-hull \\
\hline Length between Perpendicular, & 1.603 & 1.603 \\
LBP $(\mathrm{m})$ & & \\
Breadth, B (m) & 0.404 & 0.404 \\
Draft, T (m) & 0.085 & 0.085 \\
Wetted Surface Area, WSA $\left(\mathrm{m}^{2}\right)$ & 0.571 & 0.574 \\
Volume of Displacement, $\nabla\left(\mathrm{m}^{3}\right)$ & 0.0202 & 0.0204 \\
Mass $(\mathrm{kg})$ & 20.254 & 20.478 \\
\hline
\end{tabular}

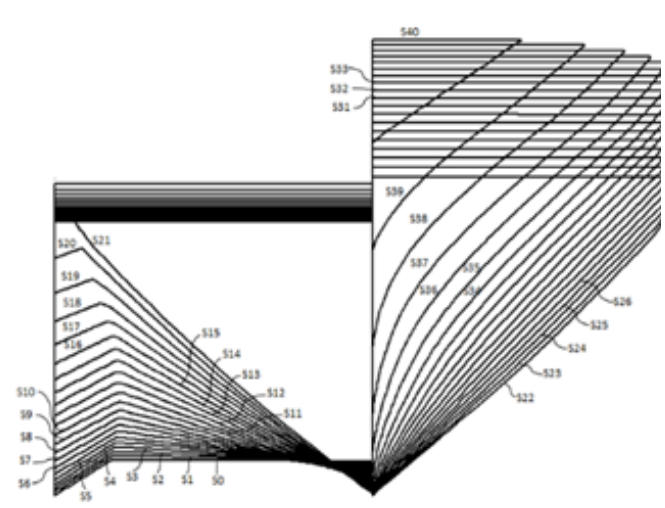

(a)

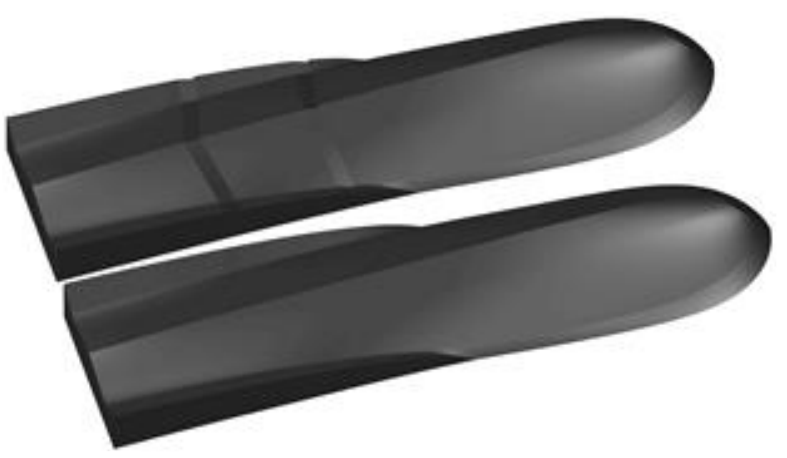

(b)

Figure 1. (a) body plan (b) rendered hull, stepped-hull (left) and without stepped-hull (right)

\section{Computational Domain and Meshing Generation}

The boundary conditions used in the project and computational domain of the monotricat model associated with the unstructured hexahedral meshes are illustrated in Figure 2. 


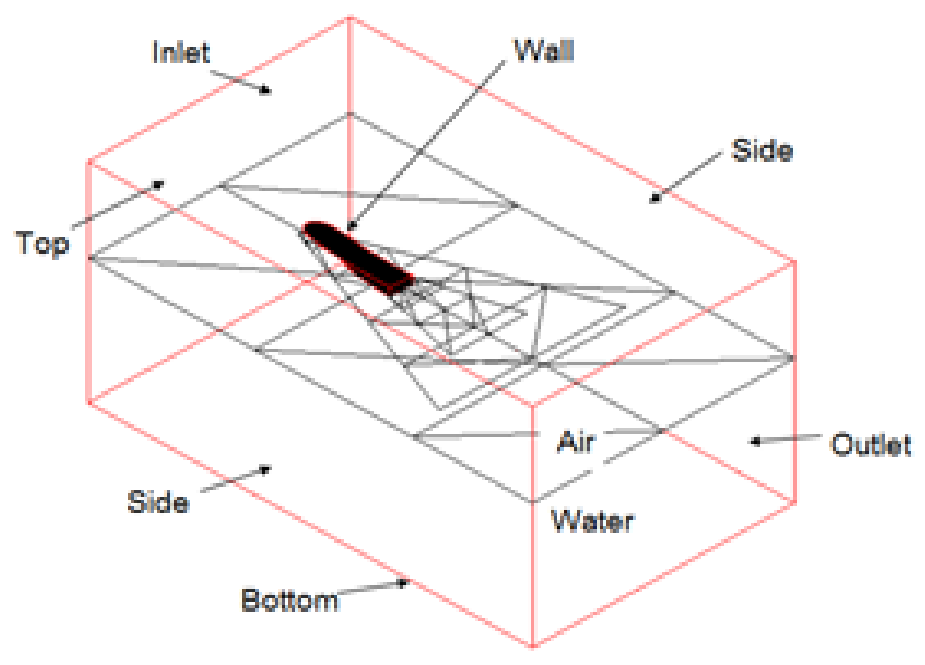

(a) Boundary condition

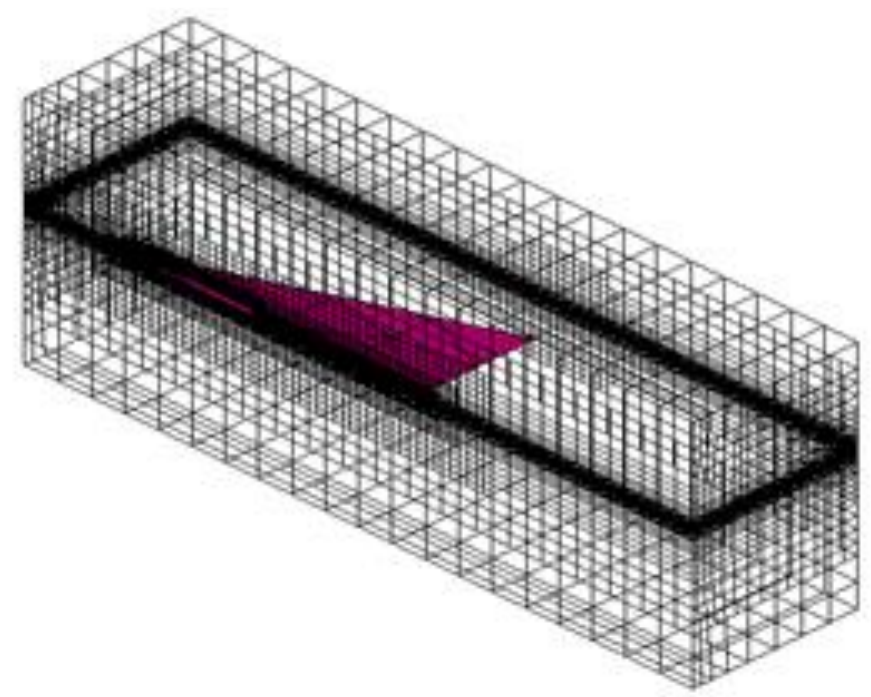

(b) Mesh generation

Figure 2. (a) boundary condition; and (b) the computational domain associated with mesh model of monotricat ship.

An extra local refinement of the mesh was added around the free surface to capture the waves that were generated by the monotricat ship hull during computation. In addition, the local refinement was employed by surrounding the global meshed computational domain. Corresponding, the maximum number of this local box refinement was set as the maximum global number of refinement. In this simulation, the local maximum number was determined as equal to 12. Meanwhile, another surface was employed as a triangle and was purposed to capture the effective area in both $\mathrm{x}$ and $\mathrm{y}$ directions, where the Kelvin waves will appear. Furthermore, the effective domains for this CFD simulation in deep water condition or infinite water depth are presented in Table 3. Considering on less computational time, the authors apply the symmetrical computational domain model (for all simulation condition). 
Table 2. Computational domain and boundary condition

\begin{tabular}{lccc}
\hline \multicolumn{1}{c}{ Description } & $\begin{array}{c}\text { Distance with respect to } \\
\text { origin point }\end{array}$ & Type & Condition \\
\hline$X_{\min }$ (Inlet) & $1.0 \mathrm{~L}_{m h}$ & EXT & Wave generator \\
$X_{\max }($ Outlet $)$ & $3.0 \mathrm{~L}_{m h}$ & EXT & Far field \\
$Z_{\min }$ (Bottom) & $1.5 \mathrm{~L}_{m h}$ & EXT & Prescribed pressure \\
$Z_{\max }($ Top) & $0.5 \mathrm{~L}_{m h}$ & EXT & Prescribed pressure \\
$Y_{\min }($ Side $)$ & $1.5 \mathrm{~L}_{m h}$ & EXT & Far field \\
$Y_{\max }($ Side $)$ & $1.5 L_{m h}$ & EXT & Far field \\
\hline
\end{tabular}

Referring to Table 2, the external (EXT) boundary type condition was assigned to treat velocity and pressure condition. In addition, the boundary condition for the top and bottom of the patches domain were assigned as 'prescribed pressure'. In this mode, the pressure was imposed during the computation initialisation, where the updated hydrostatics pressure was then applied. This means that the pressure is not constantly at 0 (zero) during the computational but it dynamically updates due to the cell mesh moving vertically towards the free surface position. Since this computational will run in the presence of wave, the inlet path will be assigned as 'wave generator' that available for regular and irregular condition. The values for the wave condition will be computed by using tool names 'waves generation info'. Concerning the boundary condition for the monotricat ship, surfaces were assigned as solid patched, where a wall-function condition was employed to these surfaces. In accordance with the best practice guidelines for marine application of NUMECA FINE/Marine 3.1-1. The average duration of every simulation was about 100 to 140 hours ( 4 parallel computations with $\Delta \mathrm{t}=0.001 \mathrm{~s}$ ) on a HP Z820 Workstation PC with processor Intel(R) Xeon(R) CPU ES-2690 v2 @ 3.00GHz (2 Processor) associated with the installed memory (RAM) of $32.0 \mathrm{~GB}$ and 64-bit operating system.

Table 3. Mesh Independent study on monotricat ship.

\begin{tabular}{cccccc}
\hline Case & $\begin{array}{c}\text { Number of } \\
\text { Division along } \\
\text { Cartesian Axis } \\
(X, Y, Z)\end{array}$ & $\begin{array}{c}\text { Initial } \\
\text { Number of } \\
\text { Cell } \\
\text { Meshing }\end{array}$ & $\begin{array}{c}\text { Total Number } \\
\text { of Cell } \\
\text { Meshing }\end{array}$ & $\begin{array}{c}\text { Heave } \\
\text { motion } \\
(\mathrm{m})\end{array}$ & $\begin{array}{c}\text { Pitch } \\
\text { motion } \\
(\mathrm{deg})\end{array}$ \\
\hline $\mathrm{A}$ & $10 \times 3 \times 5$ & 150 & 863,048 & 0.138972 & 0.45696 \\
$\mathrm{~B}$ & $13 \times 4 \times 7$ & 364 & $1,253,213$ & 0.139136 & 0.46372 \\
$\mathrm{C}$ & $15 \times 4 \times 7$ & 420 & $1,401,236$ & 0.139315 & 0.47713 \\
$\mathrm{D}$ & $20 \times 6 \times 10$ & 1,200 & $2,365,817$ & 0.139308 & 0.47781 \\
\hline
\end{tabular}

The meshing generation of the monotricat ship model was created in HEXPRESS 3.1-1 software. It should be noted that an adequate number of mesh is very important to maintain numerical accuracy and steadiness in the computational results regardless of the longer CPU time. Hence, a mesh independent study may need to be performed for each of the three different numbers of cell meshing. Referring to the mesh independent study result, the initial cell meshing of 420 was selected in all computed simulation of the monotricat model with reasonable accuracy of the CFD solution. This can be explained by the fact that the increase of initial cell meshing up to 1,200 was unnecessary due to its 
insignificant influence into the computational result of the total resistance. Here, convergence of the solution was assessed by monitoring the residuals of continuity, velocity, and total resistance force. It should be noted that the residual convergence criterion was taken as $1.11 \mathrm{e}-3$. By using a similar way, the optimum computed mesh numbers for monotricat ship was appropriately established. In the final stage of the CFD simulation, a package software in CFView was used to visualise the wave pattern/free surface elevation for all various configurations of the monotricat ship as displayed in Figure 3.

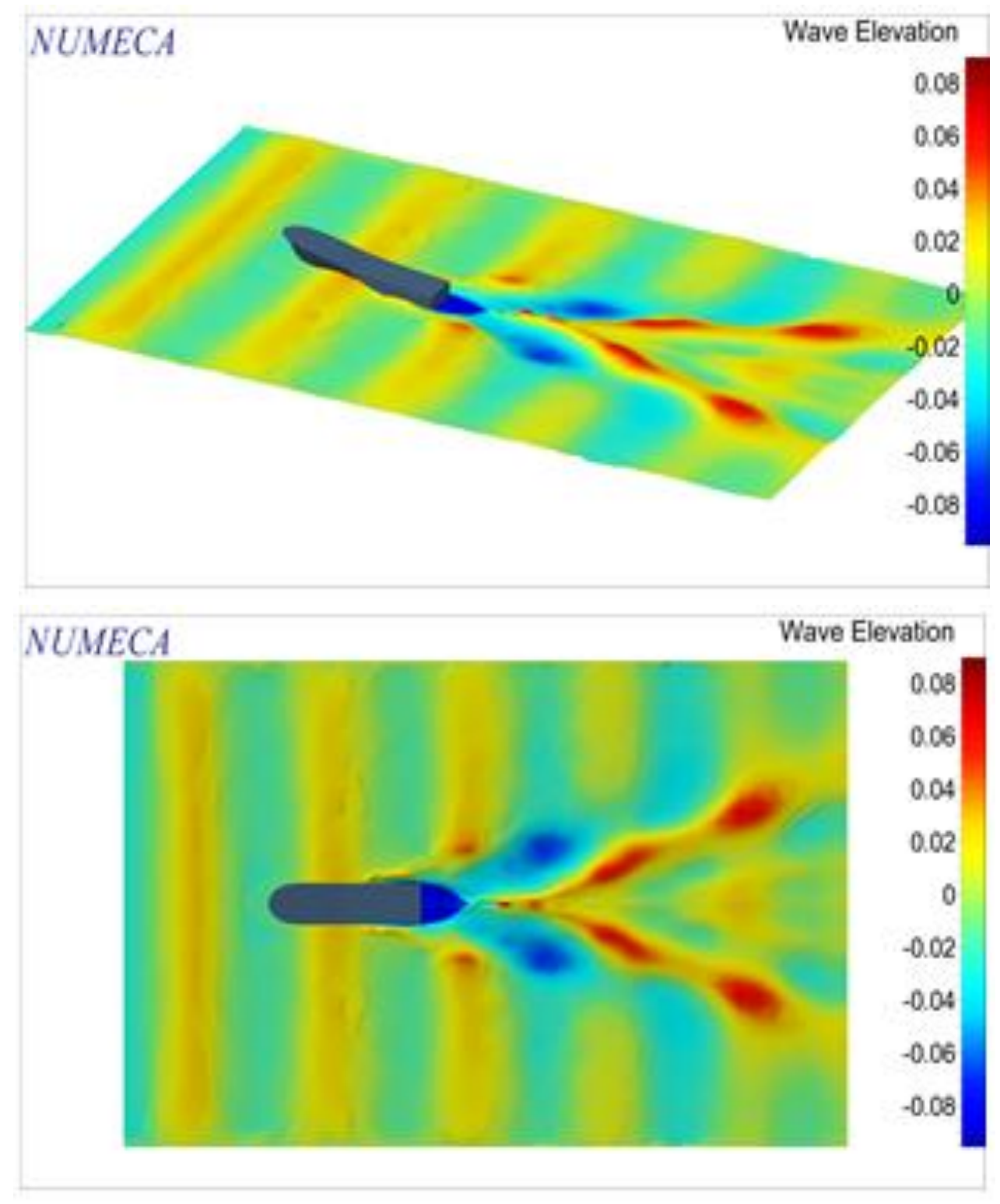

Figure 3. Free surface elevation of monotricat ship in head-sea, $\mathrm{Fr}=0.84, \lambda / \mathrm{pp}=1.0$, $\mathrm{H}_{\mathrm{w}} / \mathrm{Lpp}=0.0362, \quad \theta=180^{\circ}$

\section{RESULTS AND DISCUSSION}

The analyses for the heave and pitch motions performance of the monotricat (with and without stepped-hull configuration) in the various Fr, wave's properties (wavelength and 
wave height) have been presented and appropriately discussed. In this study, the computational fluid dynamic approach (CFD) was utilised to obtain the response amplitude operators of the monotricat ship.

\section{Effect of Froude Number (Fr)}

Referring to Figure 4, the subsequent increase from $\mathrm{Fr}=0.84$ up to 1.11 was insignificant to influence the heave and pitch motions. However, these motions subsequently increase as $\mathrm{Fr}=1.11$ until 1.39. This result analysis was reasonable since the monotricat ship geometrically provided hydrostatics support at low speed; while predominantly offered high dynamics lift at high speed [25]. Comparing to the monotricat ship without steppedhull, the heave and pitch motions of the monotricat ship with stepped-hull has lower heave and pitch motions from $\mathrm{Fr}=1.11$ up to 1.39 (see Table 4). This can be explained by the existence of stepped-hull on the monotricat ship had provided more vertical damping motions [26].
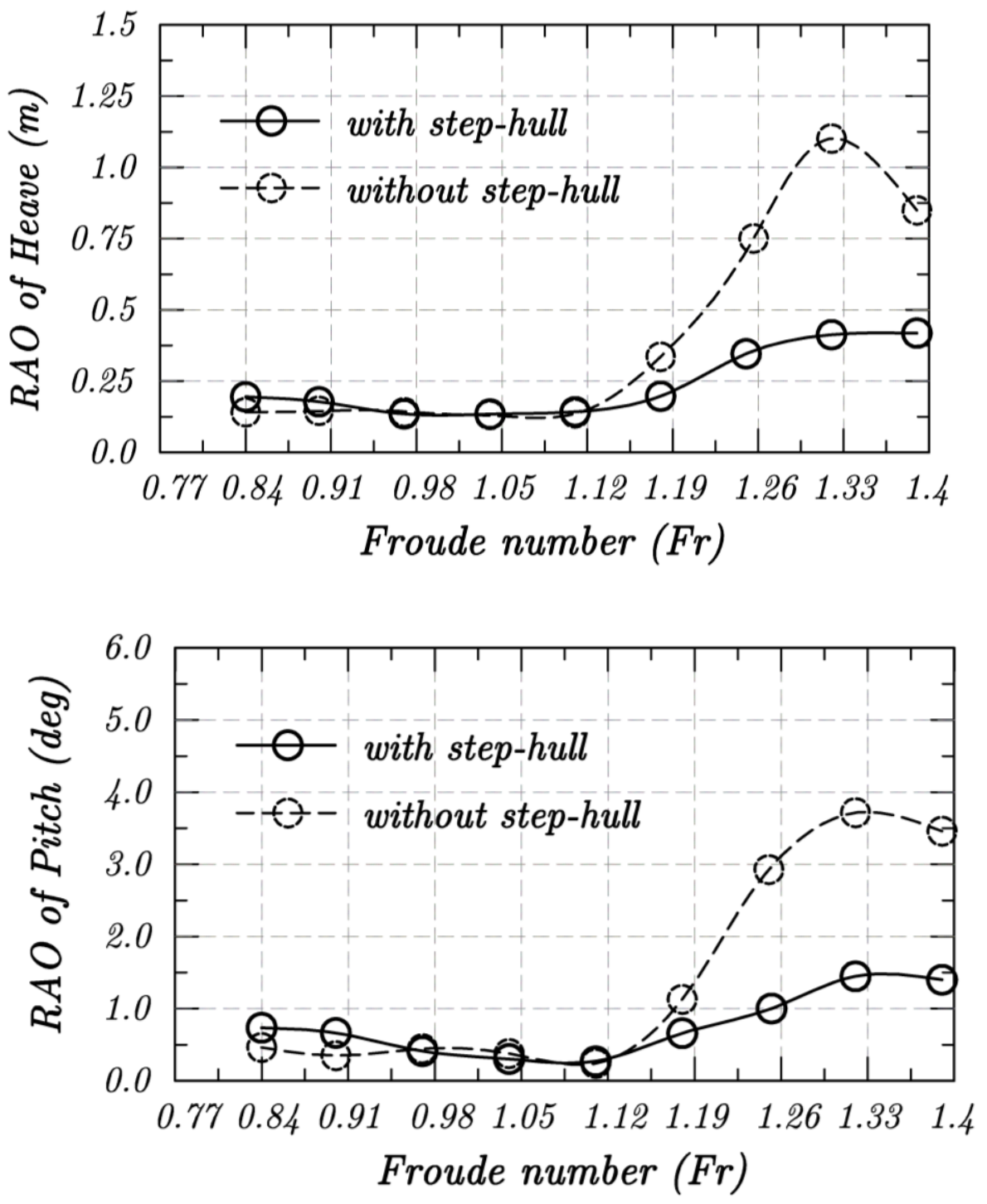

Figure 4. Heave and pitch motion for monotricat ship (with and without stepped-hull configurations) at various Froude number, $\lambda / \mathrm{Lpp}=1.0, \mathrm{H}_{\mathrm{w}} / \mathrm{Lpp}=0.0362, \theta=180^{\circ}$. 
Table 4. Heave and pitch movement for monotricat ship (without stepped-hull configurations) at various Froude number (Fr).

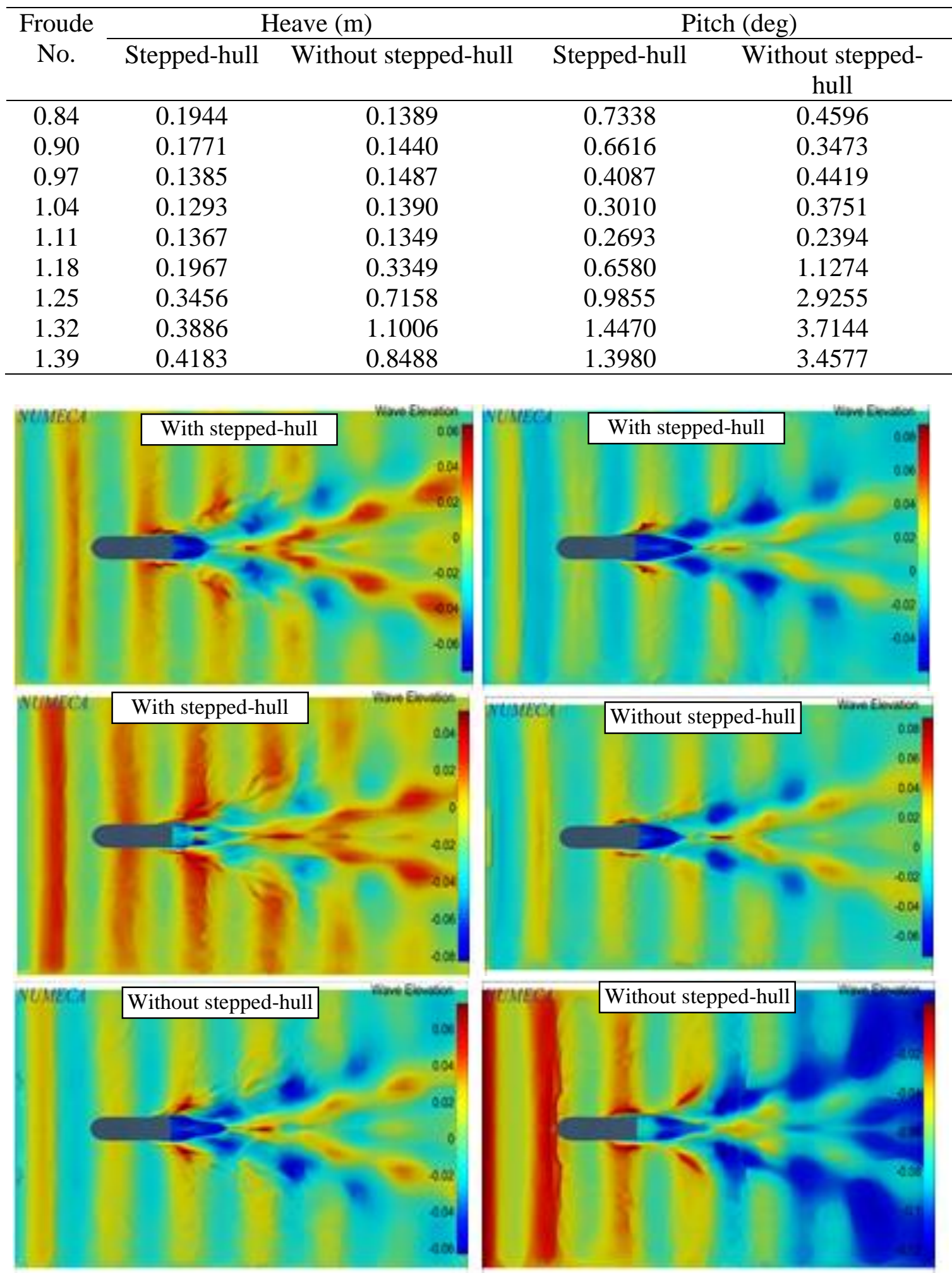

Figure 5. Free surface elevation for monotricat ship with and without stepped-hull, $\lambda / \mathrm{Lpp}=1.0, \mathrm{H}_{\mathrm{w}} / \mathrm{Lpp}=0.0362, \theta=180^{\circ}$. 
Besides that, the compressed air supplied behind the stepped-hull and the pressurised air cavity occurred due the presence of stepped-hull geometry resulted in better seakeping performance of the monotricat ship. As shown in Figure 5, the lower wave trough at the back region of the monotricat ship (blue colour) decreased as the velocity increased. It should be noted here that the presence of the stepped-hull has raised especially at $\mathrm{Fr}=1.11$, the total resistance due to existence of higher wave amplitude leads to better seakeeping ability as compared to the monotricat ship without stepped-hull [27]. In this study, the heave and pitch motions of the stepped-hull monotricat ship was analysed at various wavelength and wave heights, as displayed in Figure 6 to Figure 9, where the results are presented in the form of Response Amplitude Operators.
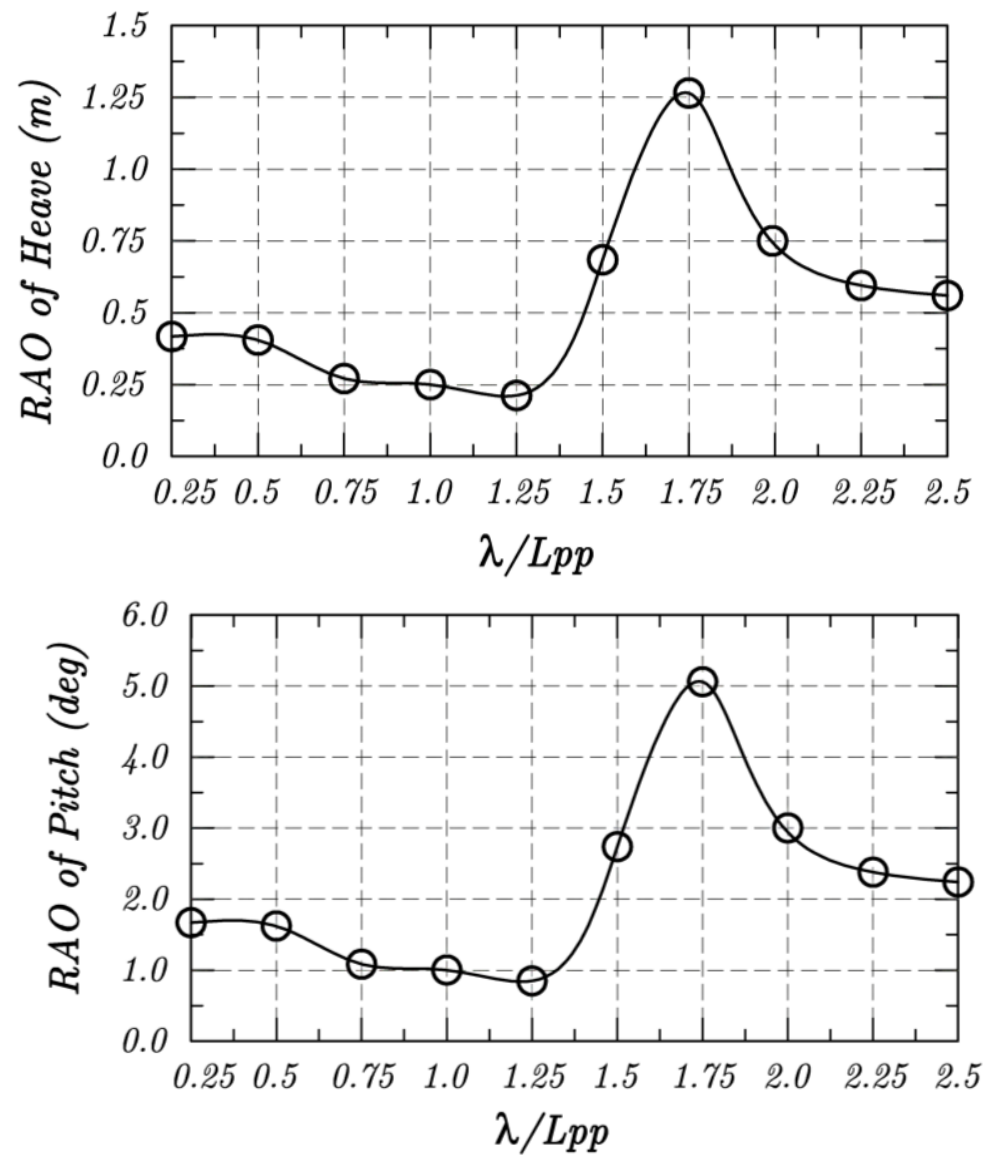

Figure 6. Heave and pitch motions for monotricat ship at various wavelength, $\mathrm{Fr}=1.1$, $\mathrm{H}_{\mathrm{w}} / \mathrm{Lpp}=0.0362$ and $\theta=180^{\circ}$

\section{Effect of Wavelengths $(\lambda /$ Lpp)}

The RAO characteristics of the heave and pitch motions were displayed in Figure 6, where the detailed results are completely presented in Table 5. In this figure, the behaviour of her heave and pitch motions were relatively steady at $\lambda / L p p=0.25$ and 0.5 . However, the heave motion decreased slightly from $\lambda / L p p=0.5$ up to 1.25 . Referring to Figure 7 , this can be explained by the fact that the lowest wave amplitude at the aft region (blue colour) resulted in a lower heave and pitch motions of the monotricat ship. Furthermore, the heave motion increased and reached a peak point at $\lambda / \mathrm{Lpp}=1.75$, then flatted out from $\lambda / \mathrm{Lpp}=1.75$ to 2.0 . It was noted here that the maximum RAO of the heave and pitch motions occurred at $\lambda / \mathrm{Lpp}=1.75$. This inherently indicated that the seakeeping performance of the monotricat ship had gradually degraded. The reason can be explained 
by the effects of resonance and exciting forces due to the incoming waves which resulted in larger motion responses. In can be concluded that RAO of the heave and pitch motions increased within the range of $0.25<\lambda / \mathrm{Lpp}<2.0$. Furthermore, the response amplitude operator for both the heave and pitch motions subsequently decreased at $\lambda / \operatorname{Lpp}>2.0$.
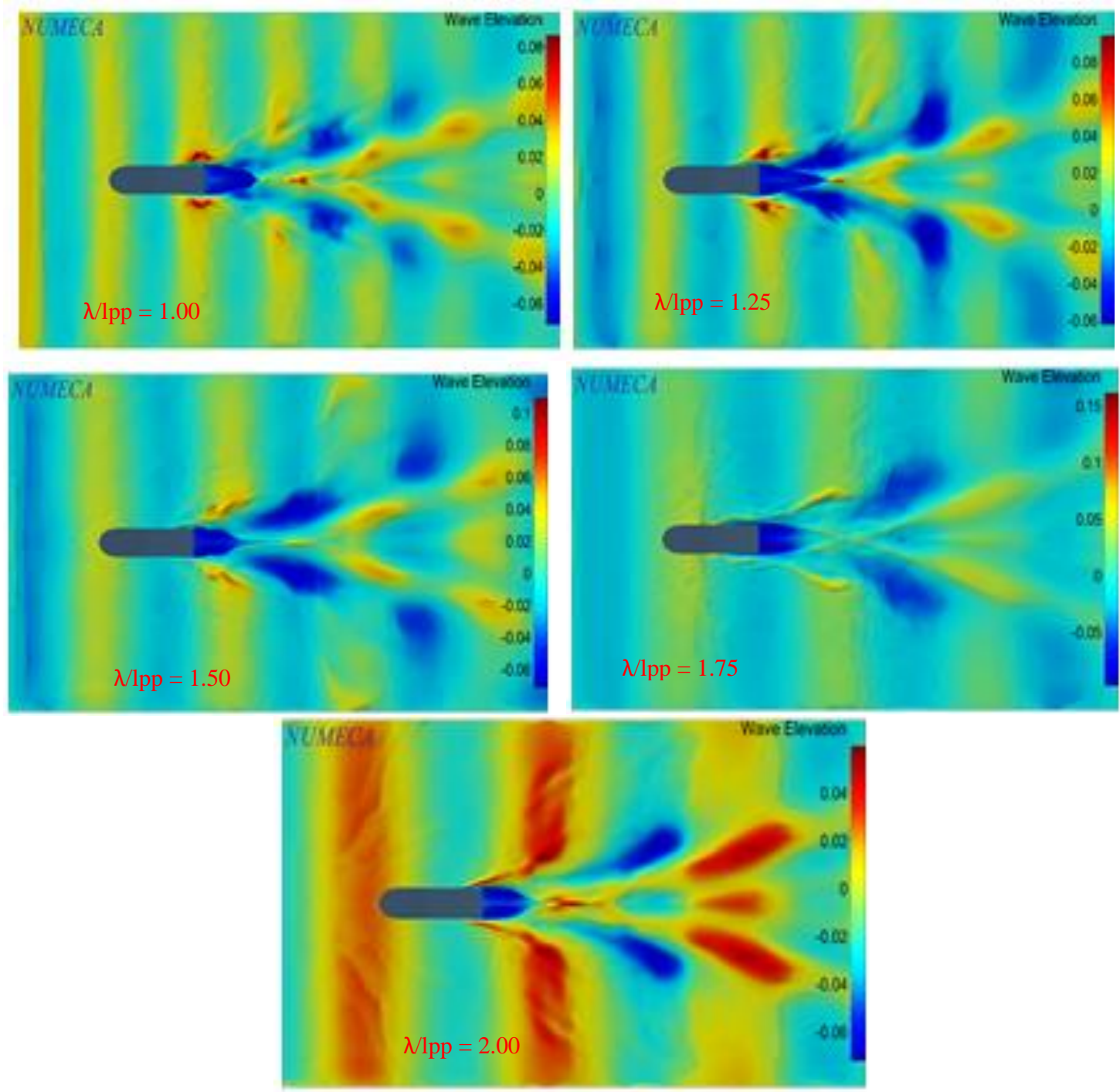

Figure 7. Free surface elevation for monotricat ship with stepped-hull in various wavelengths, $\mathrm{Fr}=1.1, \mathrm{H}_{\mathrm{w}} / \mathrm{Lpp}=0.0362$ and $\theta=180^{\circ}$

Table 5. Heave and pitch motions of monotricat ship at various wavelengths ( $\lambda / \mathrm{Lpp})$.

\begin{tabular}{ccc}
\hline$\lambda /$ Lpp & Heave motion, $(\mathrm{m})$ & Pitch motion, $(\mathrm{deg})$ \\
\hline 0.25 & 0.4169 & 2.0510 \\
0.50 & 0.4050 & 1.9344 \\
0.75 & 0.2707 & 1.4164 \\
1.00 & 0.2539 & 1.3056 \\
1.25 & 0.2117 & 0.9060 \\
1.50 & 0.6846 & 3.0320 \\
1.75 & 1.2646 & 4.9156 \\
2.00 & 0.7347 & 2.0926 \\
\hline
\end{tabular}


Table 6. Heave and pitch motions for monotricat ship at various wave heights $\left(\mathrm{H}_{\mathrm{w}} / \mathrm{Lpp}\right)$.

\begin{tabular}{ccccc}
\hline & \multicolumn{4}{c}{$\mathrm{H}_{\mathrm{w}} / \mathrm{Lpp}$} \\
\cline { 2 - 5 }$\lambda / \mathrm{Lpp}$ & 0.0144 & 0.0574 & 0.0144 & 0.0574 \\
& \multicolumn{3}{c}{ Heave $(\mathrm{m})$} & \multicolumn{2}{c}{ Pitch $\left(^{\circ}\right)$} \\
\hline 0.25 & 0.0999 & 0.4169 & 0.5028 & 2.0510 \\
0.50 & 0.0479 & 0.4050 & 0.3437 & 1.9344 \\
0.75 & 0.0449 & 0.2707 & 0.3524 & 1.4164 \\
1.00 & 0.0825 & 0.2539 & 0.3123 & 1.3056 \\
1.25 & 0.1174 & 0.2117 & 0.2707 & 0.9060 \\
1.50 & 0.3671 & 0.6846 & 1.3837 & 3.0320 \\
1.75 & 0.2031 & 1.2646 & 0.9253 & 4.9156 \\
2.00 & 0.1836 & 0.7347 & 0.7514 & 2.0926 \\
\hline
\end{tabular}
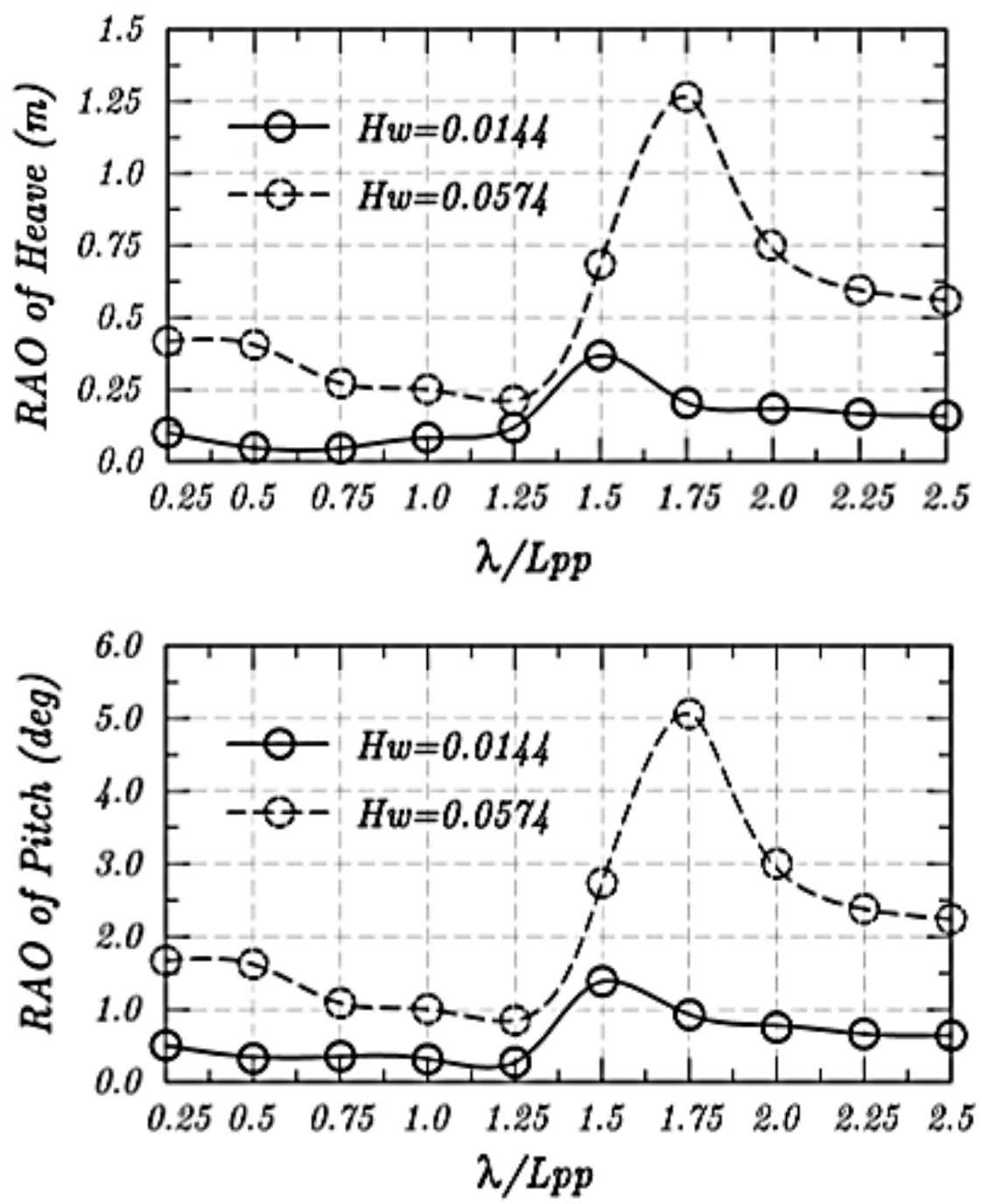

Figure 8. Heave and pitch motion for monotricat ship at various wave height $\left(\mathrm{H}_{\mathrm{w}} / \mathrm{Lpp}\right)$, $\mathrm{Fr}=1.1$ and $\theta=180^{\circ}$. 


\section{Effect of Wave Heights $\left(\mathrm{H}_{\mathrm{w}} / \mathrm{Lpp}\right)$}

Referring to Figure 8, the computational simulations were carried out to of predict RAO for the heave and pitch motions in various wave heights $\left(\mathrm{H}_{\mathrm{w}} / \mathrm{Lpp}\right)$. The results showed that the heave and pitch motions were obviously of similar trend with the results at $\mathrm{H}_{\mathrm{w}} / \mathrm{Lpp}=0.0144$ and 0.0574 . This is reasonable since the magnitude of the wave height was proportional to the heave and pitch motions responses. In other words, the increase of the wave height was proportional to local kinetic energy in the wave, acting as pressure on the floating bodies, as shown in Figure 9. This means that the higher energy would contribute more impact to the monotricat ship. In case of $\mathrm{H}_{\mathrm{w}} / \mathrm{Lpp}=0.0574$, the RAO for the heave and pitch motions of the monotricat ship will generally result in higher responses as compared to $\mathrm{H}_{\mathrm{w}} / \mathrm{Lpp}=0.0144$. Looking into the range of wave length $(\lambda / \mathrm{Lpp})$ 0.25 up to 1.25 , the monotricat ship had small RAO of the heave and pitch motions. However, the behaviour of her RAO increased within the range of $\lambda / \mathrm{Lpp}=1.5$ and 2.0 (see also Table 6). In this situation, the seakeeping behaviour of the monotricat had gradually degraded. The reason can be explained that the monotricat ship had more vigorous heave and pitch motions, which was uncomfortable for the sailing [28].
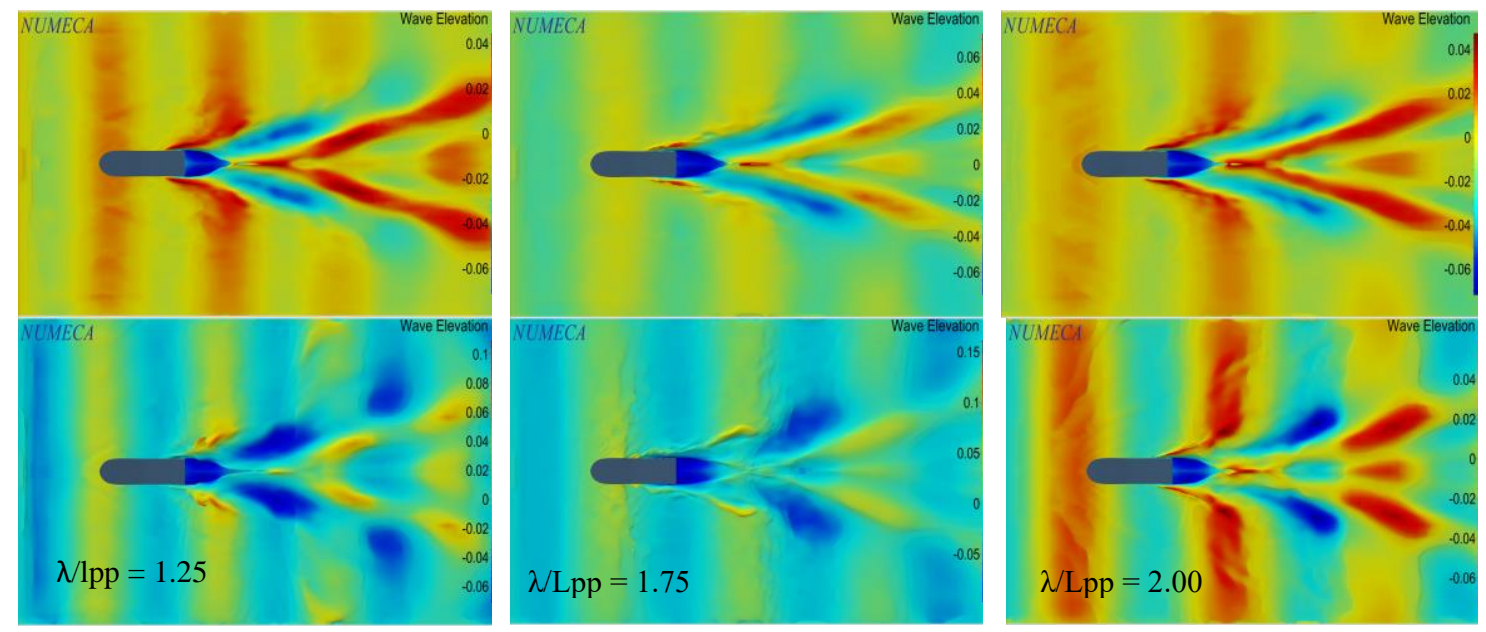

Figure 9. Free surface elevation for $\mathrm{H}_{\mathrm{w}} / \mathrm{Lpp}=0.0144$ (above) and $\mathrm{H}_{\mathrm{w}} / \mathrm{Lpp}=0.0374$ (below), $\mathrm{Fr}=1.1$ and $\theta=180^{\circ}$

\section{CONCLUSIONS}

The Computational Fluid Dynamics (CFD) simulation on predicting heave and pitch motions of the monotricat ship was performed by using FINE/Marine software. The effect of the Fr and wave properties, such as wavelengths and wave heights in head-seas regular waves, were considered. The results can be drawn as follow:

i) The increase of heave and pitch motions led to the downgrade of seakeeping performances presented in the form of high Response Amplitude Operators.

ii) As compared to the monotricat ship without stepped-hull, the monotricat ship with stepped-hull configuration has better seakeeping behaviour in respect to the increase of Fr indicated with the significant reduced heave and pitch motions responses, especially at $\mathrm{Fr}>1.19$.

iii) It was noted here that the maximum RAO for the heave and pitch motions of the monotricat ship occurred at $\lambda / \mathrm{Lpp}=1.75$. However, in the range of $0.25<\lambda / \mathrm{Lpp}<2.0$ 
and $\lambda / \operatorname{Lpp}>2.0$, the heave and pitch motions decreased, which indicated that the monotricat ship had dealt with better seakeeping performances.

iv) The increase of wave height was proportional to the heave and pitch motions that resulted in a lower seakeeping ability.

In general, the effects of Fr and wavelength on the heave and pitch motions of the monotricat ship had more complex phenomenon as compared to the wave-height with subsequent increase of wavelength and wave-height, respectively. Therefore, these CFD results are useful as preliminary prediction for navigation safety during sailing in seaway.

\section{ACKNOWLEDGEMENTS}

The authors wish to greatly thank for the special financial support from School of Ocean Engineering, Universiti Malaysia Terengganu.

\section{REFERENCES}

[1] Manchini A. New Hull New Boat, The Monotricat. In: International N, Editor.2009.

[2] Mascellaro L. Monotricat ${ }^{\circledR}$, Innovative displacement hull high hydrodynamic efficiency and energy recovery, navigating at speeds of planing hulls on spray self-produced. Journal of Shipping and Ocean Engineering. 2015;5:229-41.

[3] Faltinsen O. A rational strip theory of ship motions: Part II. University of Michigan; 1971.

[4] Fonseca N, Guedes Soares C, Maron A. Experimental and numerical hydrodynamic coefficients of a containership in heaving and pitching, maritime transportation and exploitation of ocean and coastal resources. Guedes Soares, Garbatav and Fonseca (Eds). 2005:147-55.

[5] Belknap WF. A computationally efficient method for nonlinear multihull seakeeping. ProQuest; 2008.

[6] Bailey P, Hudson D, Price W, Temarel P. Theoretical and experimental validation of the seakeeping characteristics of high speed mono-and multi-hulled vessels. Theoretical and experimental validation of the seakeeping characteristics of high speed mono-and multi-hulled vessels. 1999.

[7] Fernández RP. Seakeeping in the navigation-example in trimaran ships. International Journal for Traffic and Transport Engineering. 2012;1:221-35.

[8] Ogilvie TF, Tuck EO. A rational strip theory of ship motions: Part I. University of Michigan; 1969.

[9] Dumez F, Cordier S. Accuracy of wave pattern analysis methods in towing tanks. 21st Symposium on Naval Hydrodynamics. 1997.

[10] Islam M, Jahra F, Hiscock S. Data analysis methodologies for hydrodynamic experiments in waves. Journal of Naval Architecture and Marine Engineering. 2016;13:1-15.

[11] Ting FY, Xiang H, Kai W, Yao Z. Development of seakeeping test and data processing system. International Journal of Computational Engineering Research. 2015:33-9.

[12] Vakilabadi KA, Khedmati MR, Seif MS. Experimental study on heave and pitch motion characteristics of a wave-piercing trimaran. Transactions of FAMENA. 2014;38:13-26. 
[13] De Jong P. Seakeeping behaviour of high speed ships: An experimental and numerical study. 2011.

[14] Marcer R, Audiffren C, Dassibat C, de Jouëtte C, Guillerm P, Pettinotti B. Validation of a CFD code for ship sea-keeping simulation. The Seventeenth International Offshore and Polar Engineering Conference. 2007.

[15] Maury C, Delhommeau G, Boin J, Guilbaud M. Comparison between numerical computations and experiments for seakeeping on ship models with forward speed. Journal of Ship Research. 2003;47:347-64.

[16] Menter F. Influence of freestream values on k-omega turbulence model predictions. AIAA Journal. 1992;30:1657-9.

[17] Menter F. Performances of popular turbulence models for attached and separated adverse pressure gradient flows. AIAA Journal. 1992b;30:2066-72.

[18] Menter F. Zonal Two-equation $\mathrm{k}-\omega$ turbulence models for aerodynamic flows. AIAA 24th Fluid Dynamics Conference. 1993.

[19] Menter F. Two-equation eddy viscosity turbulence models for engineering applications. The American Institute of Aeronautics and Astronautics Journal. 1994a;32:1299-310.

[20] Spalart P, Allmaras S. A One-equation turbulence model for aerodynamic flows. 30th Aerospace Sciences Meeting and Exhibit. 1992:439.

[21] Baldwin B, Barth T. A One-equation turbulence transport model for high reynolds number wall-bounded flows. 29th Aerospace Sciences Meeting. 1991:610.

[22] Menter F, Rumsey C. Assessment of two-equation turbulence models for transonic flows. Fluid Dynamics Conference. 1994:2343.

[23] Manual NUMECA FINE/Marine: NUMECA International 2013.

[24] Seif M, Mehdigholi H, Najafi A. Experimental and numerical modeling of the high speed planing vessel motion. Journal of Marine Engineering \& Technology. 2014;13:62-72.

[25] Chaney CS, Matveev KI. Modeling of steady motion and vertical-plane dynamics of a tunnel hull. International Journal of Naval Architecture and Ocean Engineering. 2014;6:323-32.

[26] Barry CD, Duffty B. The stepped hull hybrid hydrofoil. Fifth International Conference on Fast Sea Transportation. 1999:1-15.

[27] Veysi STG, Bakhtiari M, Ghassemi H, Ghiasi M. Toward numerical modeling of the stepped and non-stepped planing hull. Journal of the Brazilian Society of Mechanical Sciences and Engineering. 2015;37:1635-45.

[28] Keuning J, Van Walree F. The comparison of the hydrodynamic behaviour of three fast patrol boats with special hull geometries. HIPER 06: 5th International Conference on High-performance Marine Vehicles: Australian Maritime College; 2006. p. 137. 